\title{
The Product and the Manufacturing of Yoghurt
}

\author{
Rajvir Singh, ${ }^{2}$ Malreddy Nikitha, ${ }^{3}$ Shwetnisha, ${ }^{4}$ Nongmaithem Mangalleima \\ ${ }^{1}$ Assistant Professor, Dept. of AH \& Dairy, Shri Megh Singh College, Abidgrah, Agra, India. \\ ${ }^{2}$ Assistant Professor, RBVRR Women College, Narayanguda, Hyderabad, Telangana, India. \\ ${ }^{3}$ M.Tech in Dairy Technology, WCDT, SHUATS, Allahabad, U.P., India. \\ ${ }^{*} \mathrm{PhD}$ scholar in Food Science and Technology, WCDT, SHUATS, Allahabad, U.P., India.
}

To Cite this Article

Rajvir Singh, Malreddy Nikitha, Shwetnisha and Nongmaithem Mangalleima. The Product and the Manufacturing of Yoghurt. International Journal for Modern Trends in Science and Technology 2021, 7 pp. 48-51. https://doi.org/10.46501/IJMTST0710007

\section{Article Info}

Received: 02 September 2021; Accepted: 28 September 2021; Published: 01 October 2021

\section{ABSTRACT}

Yogurt, often known as yoghurt, is one of the most popular fermented dairy products in the world, with a wide range of health advantages in addition to basic nutrition. In general, yogurt is a nutrient-dense food because of its nutritional profile, and it is a high-calcium source that supplies considerable amounts of calcium in bio-available form. Furthermore, it contains milk proteins with a higher biological value as well as nearly all of the essential amino acids required for optimal health. Yogurt is a probiotic carrier food that may transfer large numbers of probiotic bacteria into the body, providing unique health benefits if consumed. These are commonly referred to as "bio-yogurts." Yogurt is also said to help with lactose tolerance, immunological boosting, and the prevention of gastrointestinal problems. Consumer demand for yogurt and yogurt-related products has surged as a result of these well-known health benefits, and it has become the fastest-growing dairy category in the world. Yogurts are currently available in a variety of styles and variations, each with its own fat content, flavor profile, and texture, making them suited for a variety of meal settings and plates as a snack, dessert, sweet or savory dish.

KEYWORDS: yoghurt, milk product, probiotic, immunological boosting, gastrointestinal problems.

\section{INTRODUCTION}

An ancestral version of yoghurt first developed in Mesopotamia and Egypt around 9000 or 8000 BC, and then expanded throughout northeast Africa, the Middle East, Central Asia, and later the Balkan countries, giving a wide range of 'fermented milks.'

Yogurt is a fermented dairy product made from the fermentation of lactic acid by two species of lactic acid bacteria, Streptococcus thermophilus and Lactobacillus delbrueckii subsp. Bulgaricus. Yoghurt is a fermentative dairy product which is made of milk and is produced by lactic acid bacteria. In production of yoghurt two starters are used including Streptococcus thermophilus and Lactobacillus bulgaricus (Tewari et al., 2019).

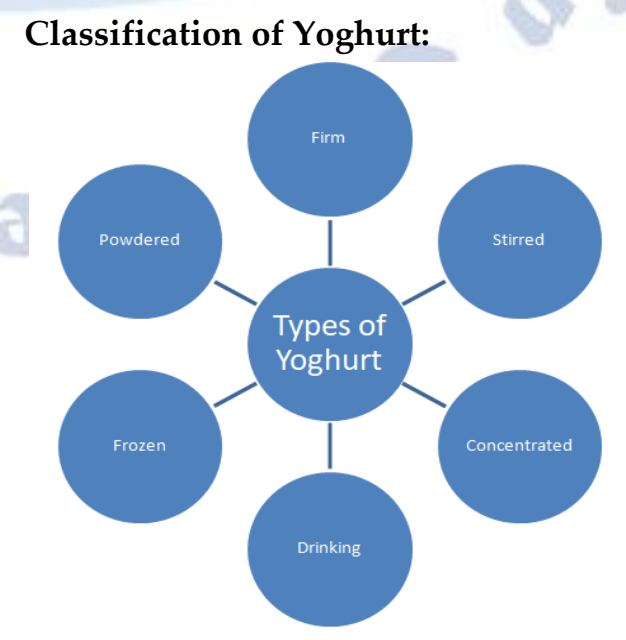

Figure 1: classification of Yoghurt 
Microbiological and Biochemical Mechanism Involved in Yoghurt Manufacture:

Microbiological Characteristics of Yoghurt:

S.thermophilus and L. Delbrueckii subp. Bulgaricus are two thermophilic lactic acid bacteria that cause yoghurt fermentation. They are gram-positive, anaerobic, aerotolerant, and catalase-negative, with no spores and a DNA concentration of less than 55 percent $\mathrm{G}+\mathrm{C}$. They can grow between 42 and 500 degrees Celsius, but not above 100 degrees Celsius.

L. Delbrueckii subsp. Bulgaricus develops as ovoit cells, whereas S. thermophilus forms linear chains of rods. They convert lactose to galactose, which is not metabolized, and glucose, which is primarily fermented to lactic acid, resulting in homo-fermentative metabolism.

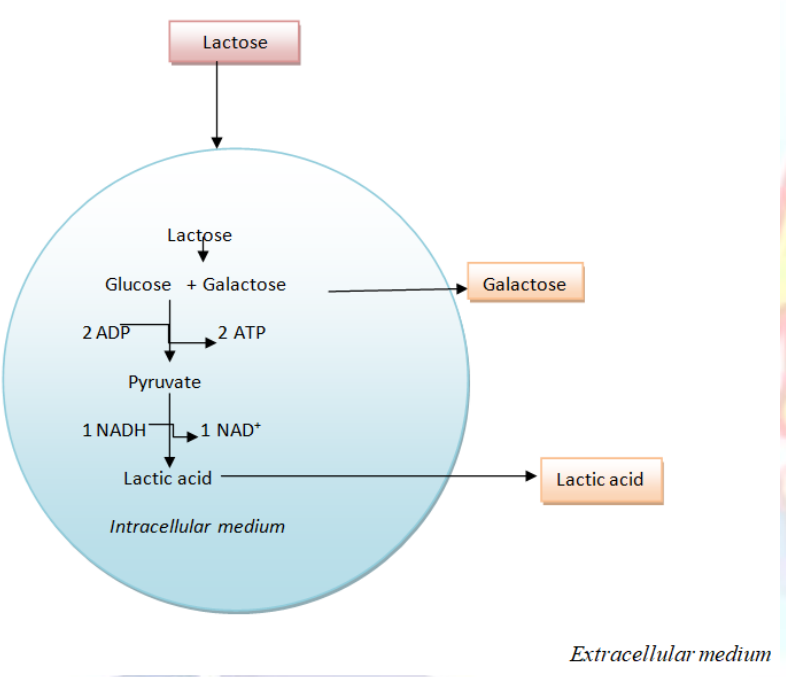

Figure 2: metabolic reactions involved in homo-fermentative metabolism in yoghurt bacteria

Biochemical and Physicochemical changes during lactic acid fermentation:

The growth of lactic acid bacteria in milk causes several modifications in yoghurt that are favorable. The formation of several metabolites (lactic acid, exopolysaccharides, and fragrance compounds), as well as the altering of the texture and nutritional content of the product, are among these changes.

\section{Flavour Compound Production:}

Due to the presence of lactic acid in the product, the flavor of yoghurt is mostly acidic. About a hundred volatile chemicals make up the scent of yoghurt, including carbonyl compounds (acids and esters), alcohols, heterocyclic, and sulphur-containing compounds. Acetaldehyde is the most important flavor ingredient in yoghurt, where it imparts a pleasant fresh and fruity scent. The majority of acetaldehyde is made directly from pyruvate via pyruvate decorbxylase or indirectly using acetyle coenzyme.

Nutritional value per 100g:

Plain yoghurt from whole milk

\begin{tabular}{|l|l|}
\hline Energy & $61 \mathrm{Kcal}$ \\
\hline Total fat & $3.3 \mathrm{~g}$ \\
\hline Saturated fat & $2.1 \mathrm{~g}$ \\
\hline Polyunsaturated fat & $0.1 \mathrm{~g}$ \\
\hline Monounsaturated fat & $0.9 \mathrm{~g}$ \\
\hline cholesterol & $13 \mathrm{mg}$ \\
\hline sodium & $46 \mathrm{mg}$ \\
\hline potassium & $155 \mathrm{mg}$ \\
\hline Total carbohydrates & $4.7 \mathrm{~g}$ \\
\hline Dietary fiber & $0 \mathrm{~g}$ \\
\hline Sugars & $4.7 \mathrm{~g}$ \\
\hline Protein & $3.5 \mathrm{~g}$ \\
\hline Vitamin A & $2 \%$ \\
\hline Vitamin & $0.8 \%$ \\
\hline Calcium & $9.3 \%$ \\
\hline Iron & $0.3 \%$ \\
\hline & $(\%$ of daily value $)$ \\
\hline
\end{tabular}

Table 1: nutritional value of yoghurt per $100 \mathrm{~g}$

Preparation of Yoghurt:

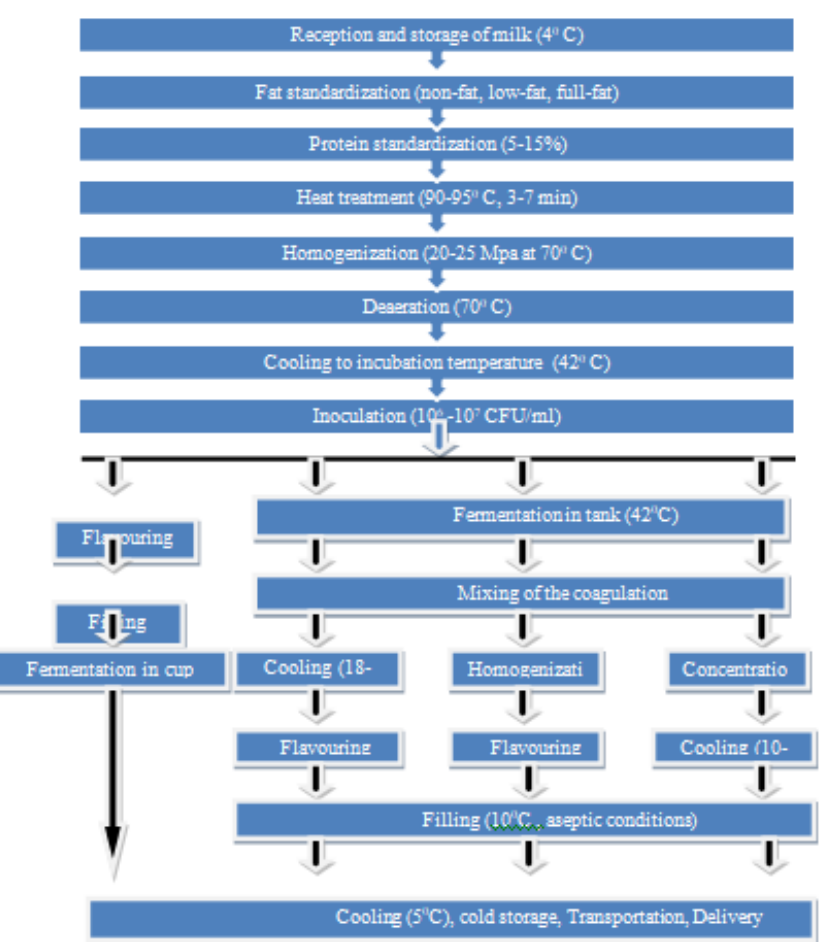

Set-Type Y. Stirred Yogurt Drinking Y. Concentrated Y.

Figure 3: schematic diagram of the production processes of different type yogurt 


\section{General Diagram for Yoghurt Manufacture:}

The industrial manufacture of yoghurt is organized along three main steps

- The preparation of the mix and homogenization, heat treatment, cooling, dearation;

- The fermentation process starting after inoculation of the mix;

- The yoghurt harvesting, post treatment and packaging depending on the steps performed atleast four types of yoghurt can be considered whose manufactur is presented in the given figure 3

\section{Preparation of Mix:}

\section{- Milk Standardization:}

Standardization of fat and protein levels, as well as the addition of sweeteners and stabilizers, are all part of the milk production process. Milk standardization is carried out at $550^{\circ} \mathrm{C}$, with additional fat content removed using a centrifugal technique. Nonfat yoghurt has a fat content of 0.01 percent, light fat yoghurt has a fat content of 1-2 percent, and whole fat yoghurt has a fat content of $>3.2$ percent. To improve the smoothness of the yoghurt and reduce syneresis, the protein level of the mix can range from 3-5 percent to up to $15 \%$. The most common method is to add milk powder, which is a simpler and more traditional method. Milk proteins are commonly used as caseinates/whey powder.

$\mathrm{FAO} / \mathrm{WHO}$ allows the use of thickeners and stabilizers (gelatine, pectin, xanthan gum, carrageen an, starch, etc.) at quantities ranging from $5-10 \%$ to improve the texture of yoghurt in some countries.

\section{- Physical treatment of Mix:}

\section{Fermentation Process:}

Heat treatment is an important part of the mixing process. Heat treatment permits spoilage microorganisms and inactive lactoperoxidises in milk to be removed. Heat treatment enhances the texture of yoghurt by permitting whey protein denaturation and interaction with casein, which reduces gel syneresis and increases gel hardness. The combination is normally heated at 90-950C for 3-7 minutes before cooling down to fermentation temperature in industrial yoghurt manufacturing.

Heat treatment is intimately linked to two additional physical treatments: mix dearation and homogenization. Before homogenization, vacuum dearation is usually done at $700 \mathrm{C}$. The mix is homogenized at a high pressure $(20-25 \mathrm{MPa})$ at a temperature near 700C. For high fat yoghurt, double stage high pressure homogenizers are advised.

\section{- Inoculation of mix:}

Yogurt is made on a large scale by inoculating a mix with concentrated starter cultures of the two yoghurt bacteria (S. Thermophilus and L. delbrueckii subsp. Bulgaricus). Commercial starter cultures are made up of precise blends of well-defined strains with a concentration more than 1010 colony-forming units (CFU)g 1, and are frozen or freeze-dried formulations. The bacteria in the injected mix are usually 106-107 CFU $\mathrm{ml}$ 1. After mixing, it is either transported to the fermentation tanks (for the production of stirred, sipping, or concentrated yogurt) or immediately to the packaging machine (for the production of fermented yogurt in cups) (for set-type yogurt manufacture).

\section{- Fermentation steps}

Several characteristics change as time passes during the lactic acid fermentation of milk. S. thermophilus is the first to grow, followed by L. delbrueckii subsp. bulgaricus, with final concentrations approaching 109 CFU g 1. Lactose and nitrogenous substances are consumed by both strains, allowing them to thrive and accumulate a variety of important metabolites. The most important ones are lactic acid, galactose, acetaldehyde, and exopolysaccharides, which contribute to the yogurt's flavor and texture. The production of extracellular lactic acid causes an acidification of the mixture, resulting in a $\mathrm{pH}$ drop from 4.8 to 4.5. Fermentation culture was added in a concentration of around $2 \%$. The fermentation process might take anything from 3 to 20 hours.

\section{Health Benefits of Yoghurt:}

- Active cultures may help the gut.

- Some probiotic strains may boost the immunity system (Tewari et al., 2020).

- It may help prevent osteoporosis.

- May reduce the risk of high blood pressure.

- A high protein food (specially Greek style).

- Can help you recover faster after a workout. 


\section{REFERENCES}

[1] Aureli P, Capurso L, Castellazzi AM, et al. (2011) Probiotics and health: an evidencebased review. Pharmacological Research 63: 366-376.

[2] Be'al C and Helinck S (2014) Yogurt and other fermented milks. In: Ray RC and Montet D (eds.) Microorganisms and fermentation of traditional foods, pp. 139-185. Boca Raton, FL: CRC Press.

[3] Benezech T and Maingonnat JF (1993) Flow properties of stirred yogurt: structural parameter approach in describing time-dependency. Journal of Texture Studies 24: 455-473.

[4] Cheng H (2010) Volatile flavor compounds in yoghurt: a review. Critical Reviews in Food Science and Nutrition 50: 938-950.

[5] Cordoba, Argentina: FAO/WHO. FAO/WHO (2011) Codex Alimentarius: codex standards for fermented milks 243-2003. In: FAO/WHO (ed.) Milk and milk products, 2nd ed., pp. 6-16. Rome: FAO/WHO. Lee WJ and Lucey JA (2010) Formation and physical properties of yogurt. Asian- Australasian Journal of Animal Sciences 23: 1127-1136.

[6] Corrieu, G., Spinnler, H. E., Jomier, Y. and Picque, D. (1988). Automated system to follow up and control the acidification activity of lactic acid starters. Fr. Pat. 2629612.

[7] Courtin P, Monnet V, and Rul F (2002) Cell-wall proteinases PrtS and PrtB have a different role in Streptococcus thermophilus/Lactobacillus bulgaricus mixed cultures in milk. Microbiology 148: 3413-3421 FAO/WHO (2001) Health and nutritional properties of probiotics in food including powder milk with live lactic acid bacteria: report of a joint $\mathrm{FAO} / \mathrm{WHO}$ expert consultation.

[8] Ruas-Madiedo P and de los Reyes-Gavila'n CG (2005) Methods for the screening, isolation, and characterization of exopolysaccharides produced by lactic acid bacteria. Journal of Dairy Science 88: 843-856.

[9] Saint-Eve A, Levy C, Le Moigne L, Ducruet V, and Souchon I (2008) Quality changes in yogurt during storage in different packaging materials. Food Chemistry 110: 285-293.

[10] Shiby VK and Mishra HN (2013) Fermented milks and milk products as functional foods - a review. Critical Reviews in Food Science and Nutrition 53: 482-496.

[11] Sodini I, Remeuf F, Haddad S, and Corrieu G (2004) The relative effect of milk base, starter, and process on yogurt texture: a review. Critical Reviews in Food Science and Nutrition 44: 113-137.

[12] Tamime AY and Robinson RK (2007) Yoghurt: science and technology. Boca Raton, FL: CRC Press.

[13] Tewari, S., \& Nakhale, S. (2020) Probiotic Microorganisms and Lactose Intolerance (LI): A Review. IX (IV), 66-72.

[14] Tewari, S., (2019). Therapeutic diet to control diseases, AkiNik Publications, 1-79.

[15] Tewari, S., David, J., \& Gautam, A. (2019). A review on probiotic dairy products and digestive health. J. Pharmacogn. Phytochem, 8 , 368-372.

[16] Tewari, S., Ramkrishna, K. S., \& Dhiman, T. (2020). A review on nutraceutical: the combination of nutrition and pharmaceutical. World Journal Of Pharmacy And Pharmaceutical Sciences, 9 (5), 2020, 1899-1906.
[17] Vinderola CG, Mocchiutti P, and Reinheimer JA (2002) Interactions among lactic acid starter and probiotic bacteria used for fermented milk products. Journal of Dairy Science 85: 721-729.
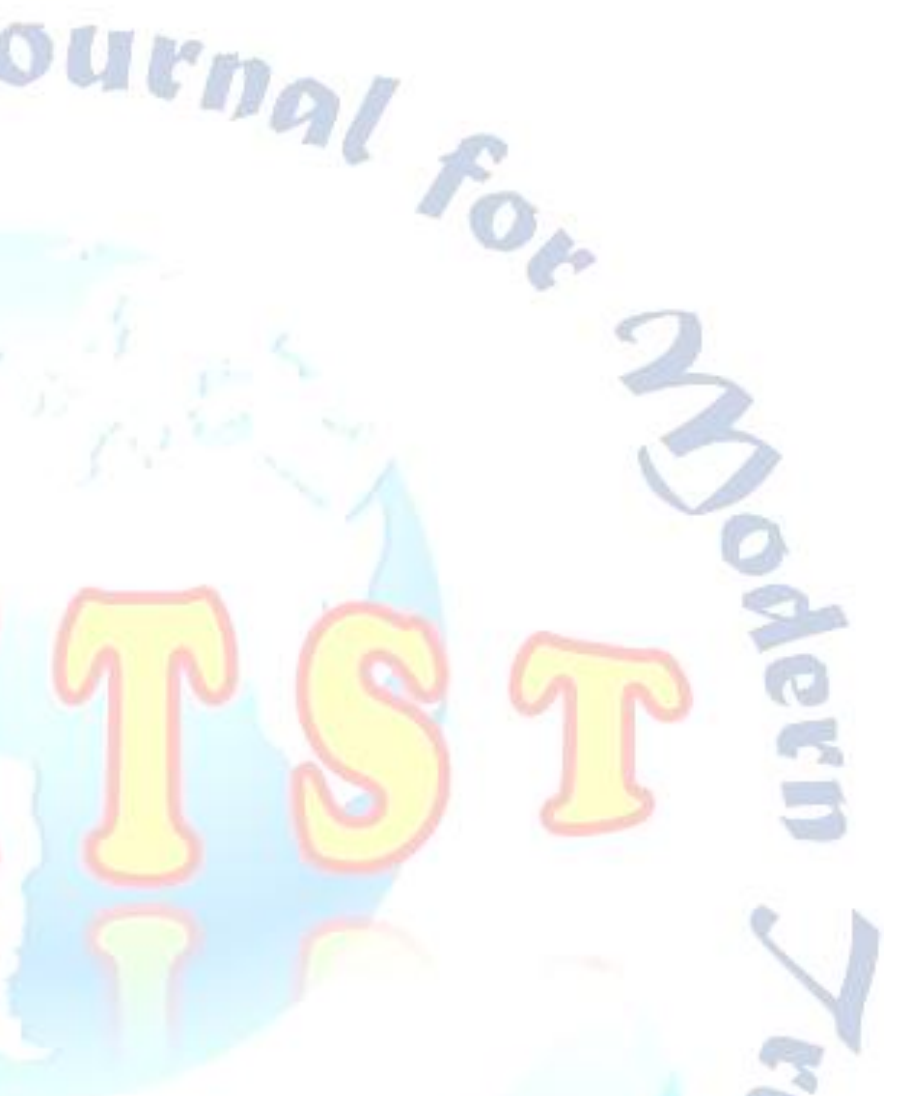